\title{
A COGNITIVE STUDY OF METAPHOR TRANSLATION IN "TRAVELLING FAR AWAY FROM MT. JINGMEN"
}

\author{
Huang, Shanshan, \\ Wang, Fengi \\ School of Foreign Studies, \\ Yangtze University, \\ Hubei Province, 434023, \\ P. R. China
}

\begin{abstract}
:
“Travelling Far Away from Mt. Jingmen" (渡荆门送别) is written by Li Bai, a famous poet of the Tang Dynasty, on his way out of Sichuan. As a masterpiece of Li Bai's poetry, the poem is full of imagination, making people unconsciously indulge in it. Since half lines of the poem are related to metaphors, this paper makes a detailed study of the metaphors in the poem and their English translations based on Conceptual Metaphor Theory and Image Schema Theory, and points out some characteristics of metaphor translation in the poem.
\end{abstract}

Keywords: "Travelling Far Away from Mt. Jingmen"; metaphor translation; conceptual metaphor theory; image schema theory; characteristics

\section{Introduction}

At the early dawn of medieval Europe, the Tang Dynasty was one of the richest and most powerful eras in the world and poetry was the greatest artistic attainments during that period (Obata, 1922: 1). Until now, Tang poetry still represents the highest level of classical Chinese poetry which is the treasure of splendid Chinese cultural heritage. Poets emerged in large numbers in the Tang Dynasty, but the fact that Li Bai can be picked out as the greatest of them is undeniable. "Travelling Far Away from Mt. Jingmen" is created by Li when he first left Sichuan. The poem which is easily ignored well combines the characteristics of landscape poetry (山水) and farewell poetry (送别诗) by his romantic poetic style. What's more, most of the poetic imagery in this poem is closely connected with metaphors which serve the theme from different perspectives. For this reason, this study tries to take a close look at those metaphors and compare their different translations, aiming to find out effective ways to render metaphorical expressions in poetry. As various English versions of the poem have been given by translators from the metrical verse school and the free verse school, the authors selected generally acceptable English

i Correspondence: email wangfeng@yangtzeu.edu.cn 
translations of metrical and free styles respectively to conduct the comparative study under the guidance of cognitive linguistic theories.

\section{Previous Studies on Metaphor Translation in Poetry}

Metaphor has received considerable attention for its universality in language use, especially in poetry. Thus, poetry is also regarded as a "metaphoric language" (Shu Dingfang, 2000). Metaphors in poetry tend to be explained from the cognitive aspect (Liu Yu, Yang Wendi, 2011). Since conceptual metaphor can be used to interpret poetry, it can also be used in poetry translation. Yan Minfen (2002) holds that it's conceptual metaphor that makes poetry translation possible. Based on a number of translation examples, Quan Xunlian and Tian Debei (2012) discuss the English translation of images in Chinese ancient poetry under the guidance of Conceptual Metaphor Theory and propose relevant strategies. He Jie and Luo Tianni (2016) choose one type of conceptual metaphor to discuss its translation in poetry, and some cited examples belong to Chinese ancient poetry. Tang Jun and He Tingting (2019) emphasize the importance of a poem created by a famous poet in the Tang Dynasty and thus conduct a comparative study on the image translation of it from the perspective of conceptual metaphor. From these previous studies, we can see that conceptual metaphor gives us a good perspective to study poetry translation. As Tang poetry represents the highest level of classical Chinese poetry, we might as well pick up one or more poems from it as an example to conduct a comparative study. In addition, the translations from metrical translators and free-verse translators should be considered.

\section{About the Poem}

According to Tomohisa (1983:1), a famous Japanese sinologist, Li Bai's life is almost that of a traveler's. Before the age of 24, the poet had been living in his hometown of Sichuan. As he was fond of writing poems, at the age of 18, he created the poem Calling on a Taoist Recluse in Daitian Mountain without Meeting Him (访戴天山道士不遇). He left his hometown at the age of 24, and then began a long journey. On the way, he wound write poems about what he saw and heard, which revealed his philosophy of life.

The poem "Travelling Far Away from Mt. Jingmen" was written when he left Sichuan for the State of Chu. His boat passed by Yuzhou (渝州) and the Three Gorges (三峡), then he came to Mt. Jingmen (also the Jingmen Mountain, 坪门山) which blocks the way to the State of Chu. After crossing the river at the foot of the mountain, Li Bai came into the land of Chu. This poem depicts what he saw after passing the Jingmen Mountain and expresses the poet's feeling of homesickness. As one of Li Bai's farewell poetry, "Travelling Far Away from Mt. Jingmen" is regarded as "a great poem of the Tang Dynasty" by the critic Hu Yinglin (胡应麟) of the Ming Dynasty. It's worth noticing that there is a word “送别 (farewell)" in the title, but we can't find obvious expressions of such emotion in the poem. Maybe it's the charm of Li's poems that distinguishes him from other poets. 


\section{Free-verse Translations and Metrical Translations}

In his doctoral dissertation, Wang Feng, supported by the views of Chinese and foreign scholars, concludes that both the metrical translators and the free-verse translators almost agree with the view of translating poetry into poetry (2015: 86). However, there are different opinions between them on whether to adopt the free style or the metrical style in translating poems. According to the metrical verse school, it can be concluded that "metrical pattern is the soul of poetry". But the free verse school points out that "metrical pattern impairs poetic significance". The question is not settled and there are actually good translations in both metrical verse and free verse. In this paper, the chosen English translations of the poem include three translations by $\mathrm{Xu}$ Yuanchong, Zhao Yanchun and Liu Junping who are representatives of the metrical verse school, and three translations by Shigeyoshi Obata, Rewi Alley and Witter Bynner \& Kiang Kang-hu who are representatives of the free verse school.

\section{Conceptual Metaphor Theory and Image Schema Theory}

As metaphor and image schemas interact in the conceptualization of human experiences, both Conceptual Metaphor Theory and Image Schema Theory will be applied in the process of analyzing the poem and its translations.

\subsection{Conceptual Metaphor Theory}

Conceptual Metaphor Theory is first put forward by George Lakoff and Mark Johnson (1980) in their masterpiece Metaphors We Live By. The main idea of the theory is that metaphor is not just a matter of language, but a matter of thinking. Conceptual metaphor is related to conceptual domains that are called the source domain and the target domain. The target domain is regarded as the conceptual domain to be conceptualized, while the source domain is the conceptual domain used to conceptualize the target domain. Many scholars have offered their thoughts on the definition of conceptual metaphor, so we can conclude that conceptual metaphor is a process by which the target domain of experience is structured in terms of the source domain of experience after comparison or judgment. More specifically, the characteristics and properties possessed by the source domain can be mapped onto those of the target domain.

\subsection{Image Schema Theory}

As early as 1980, Lakoff and Johnson mentioned the concept of image schema when they talked about Conceptual Metaphor Theory in Metaphors We Live By. Later, the concept of image schema is put forward. In his book The Body in the Mind, Johnson (1987) believes that image schemas originate from human's embodied experiences. And our conception of image schemas is a key in explaining the embodied origins of our understanding. Different scholars have different opinions about the definition of image schemas, but their core idea is consistent: Image schemas are schematizations (i.e., abstractions) of spatial experience. When it comes to Image Schema Theory, classification of image schemas is unavoidable. On the one hand, the inventory of image schemas, according to the cognitive linguists, is never exhaustive. On the other hand, image 
schemas can be divided into basic ones and complexed ones which are formed by the former ones such as the CONTAINER Schema, the LINK Schema, the SOURCE-PATH-GOAL Schema and the UP-DOWN Schema (Wang Yin, 2007: 177).

\section{An Analysis of Metaphors in the Poem and Their Translations}

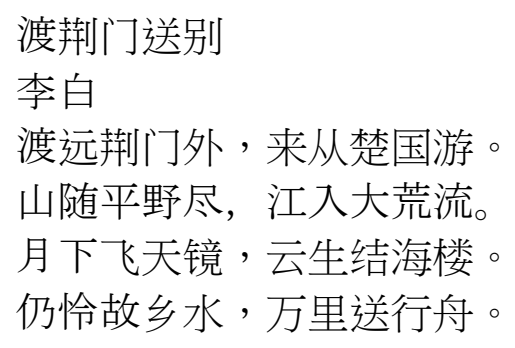

There are two types of metaphors in the poem: one exists in the form of the source domain, the other in the form of both source domain and target domain. The metaphor in the title and those in the last line belong to the former type, and the metaphors in the third line belong to the latter. First of all, the title "Travelling Far Away from Mt. Jingmen" can be regarded as a metaphor because "Farewell at Mt. Jingmen" as the title shows metaphorically means "saying goodbye to hometown" which doesn't exist in the title. Likewise, in the last line, the metaphor People Is Water can be found although the target domain doesn't exist in the line. Finally, in the third line, there are metaphors whose two domains exist.

\subsection{Metaphor in the Title and Its Translations}

Just as mentioned earlier, the poem is created when the poet left his hometown for a long journey which forms a PATH Schema. The starting point is his hometown in the State of Shu and the endpoint is the State of $\mathrm{Chu}$, passing by Yuzhou, the Three Gorges and the Jingmen Mountain. From the sequence of contiguous locations connecting the source with the goal, we can see that the Jingmen Mountain is one of these locations, but it is the only one in the title. According to historical records, Jingmen (荆门) or the Jingmen Mountain which is in present-day Hubei Province has been known as an important area connecting the State of Chu and the State of Shu since ancient times. That is to say, after passing the Jingmen Mountain the poet will enter the land of $\mathrm{Chu}$ as a foreigner. Thus, farewell at Mt. Jingmen as the title shows metaphorically means saying goodbye to hometown. This kind of artistic expression is favored by Li Bai who is wellknown for his romantic poetry, and we can also find similar uses in Li's other poems. Next, let's look at the translations of the title.

Xu: Farewell beyond the Thorn-Gate Gorge ${ }^{(1)}$

(1) In present-day Hubei Province.

Zhao: Farewell at Mt. Chastegate

Liu: Across the Jingmen Mount

Obata: Parting At Ching-Men

Alley: Farewell at Chingmen 


\section{Bynner \& Kiang: Bidding A Friend Farewell At Ching-Mên Ferry}

As the title metaphorically means saying goodbye to hometown, the source domain is "farewell at Mt. Jingmen" and the target domain is "saying goodbye to hometown". Having observed the above translations, we can see that all the translators render the source domain into English except Liu. First, let's look at the translation methods used by them. We can see the translation method of literal translation is used by all these translators. Besides, $\mathrm{Xu}$ also adopts annotation to explain where the Thorn-Gate Gorge (珜门) is. Liu omits the word “送别” in his translation and Bynner \& Kiang adopt amplification to find out the person to whom the poet bids farewell. In light of the above differences, we can suppose that $\mathrm{Xu}$ wants to help the target language readers understand the name of an ancient place which is important for them to understand the poet's intention. However, Xu's annotation fails to tell the readers the fact that the Thorn-Gate Gorge has been an important area connecting the State of Chu and the State of Shu since ancient times, and the readers can hardly be aware of the poet's homesickness without this knowledge. As for Liu's translation "Across the Jingmen Mount", there is no "farewell", which is different from other translations. The reason can be found in his translation of verse lines where he points out the relation between the Jingmen Mount and the poet's hometown. To avoid repetition, the translator doesn't translate the word “送别” in the title. In this way, Liu's translation of the title can also convey the poet's intention in an indirect way. Bynner \& Kiang seem to have a question about the person the poet bids farewell to and try to give their assumption that the person is one of the poet's friends. Their assumption is reasonable because there may be friends, families and so on in the poet's hometown. In a word, the source domain is kept and translated by almost all translators. What's more, because the name of a place which is a key point in metaphor understanding is not familiar to all the target language readers, appropriate annotation can be adopted.

\subsection{Metaphors in the Lines “仍怜故乡水, 万里送行舟” and Their Translations}

From the first line to the third line, we can see no word used to convey both attitudes and feelings of the poet. However, he expresses his preference for hometown and reluctance of leaving home in the last line. In fact, the poet has been preparing for the final burst of emotions. At the very beginning, the poet introduces the route and the landscape along the way, creating a pleasant atmosphere. Although everything before his eyes is attractive, the poet as a wanderer prefers things in hometown such as the flowing water. There are two metaphors that are intertwined together here: People Is Water; Water Is People. The metaphor Water Is People is a typical ontological metaphor which is used to understand our experiences as familiar entities or substances that we can refer to, categorize and construe ( Lakoff \& Johnson, 1980). By the metaphorical mapping, some elements of the domain of PEOPLE are mapped onto those of the domain of Water, and thus the flowing water possesses the human's action “送 (see off)". What's more, “故乡水 (the flowing water from homeland)" here is symbolic of people in homeland who cannot see him off. Thus, the flowing water from homeland becomes a common metaphoric image. Now, let's look at the translations of the last line. 
Xu: The water that from homeland flows

Will follow me where my boat goes.

Zhao: $\mathrm{O}$ my dear mountain and water

See my boat go far and farther.

Liu: The same water by my boat arouses my tender love,

That sees my sail from my land thousand miles rove.

Obata: I bid you farewell. Ten thousand li you sail away,

But it is the waters of the home river that bear you on.

Alley: all beautiful yet none as lovely as my old home;

no matter how far I roam, ever I wish to take a boat and return again.

Bynner \& Kiang: And the water has brought you a touch of home

To draw your boat three hundred miles.

From the above translations, we can find that there are no metaphorical expressions in the translation of Obata. In his translation, people and water are regarded as separate items and there is no mapping between them. Among all the other translators, Alley changes the original metaphor in his translation. More specifically, the metaphor is changed into a simile in translating, and the source domain is changed into the beauty of hometown and the target domain is changed into the beauty of other things. By doing this, the metaphoric effect in the original may be weakened. As the verb “送" in the original whose meaning is "see off" is very important for the mapping between the source domain and the target domain, there are different translations of it by the rest four translators. Xu translates the word "送" into "follow" which has the similar metaphoric effect in the target language. Then, both Zhao and Liu translate the word into "see" which is the same as "see off". However, Bynner \& Kiang translate the word into "draw" which doesn't have the similar metaphoric effect in the target language. To sum up, most translators reproduce the metaphors in the target language in various degree, and the translations in which the source domain is kept and translated are more faithful to the form and meaning of the original.

\subsection{Metaphors in the Third Couplet and Their Translations}

When the poet came into the land of $\mathrm{Chu}$, he enjoyed a variety of landscape that inspired him to write verse lines “月下飞天镜, 云生结海楼” which are full of imagination. The original expression is too concise to understand, so we referred to A Dictionary of Li Bai's Poetry Appreciation (李白诗歌鉴赏辞典) and found that this couplet vividly depicted what the poet saw day and night. In the evening, the moon is like a mirror; in the daytime, the clouds in the sky are like mirages. That's the core idea of the original because the images in the line “月下飞天镜” are complex. What does “月下” mean? And what does “飞天镜” mean? First, in the poet's mind, the moon is like a mirror. Thus, the mirror in the sky (天镜) is the moon. Last, the reflection of the moon in the water (月下) is the mirror in the sky flying down (飞天镜). In the first metaphor, the source domain is a mirror and the target domain is the moon. In our mind, the moon is in the sky, so the image schema of the moon is UP; a mirror is in one's house, so the image schema of a mirror is Down. Thus, a mirror that must be in the sky can be used to refer to the moon, and thus 
the moon in the water is just like the mirror in the sky flying down. In “月下飞天镜”, the source domain is "the mirror in the sky flying down" and the target domain is "the reflection of the moon in the water". And both domains exist in the couplet. Next, let's look at the translations of “月下飞天镜” first.

Xu: The moon, celestial mirror, flies;

Zhao: The moon shines, a mirror to be;

Liu: From the moon into the water plunges a Heaven Mirror,

Obata: Now under the moon like a mirror flying through the sky,

Alley: I look at the wonder of the moon in heaven, seeming to me like a flying mirror;

Bynner \& Kiang: The moon is lifted like a mirror,

According to the characteristics of the translations, we can see three translators of the metrical verse school tend to keep the original metaphor in the target language; three translators of the free verse school tend to change the metaphor in the source language into a simile in the target language. In addition, as the line is not easy to understand, misunderstanding is unavoidable in translating. Obata seems to translate the expression word by word, which violates the rules of the target language and can hinder comprehension. Having analyzed it, let's turn to the translations of “云生结海楼”.

Xu: The clouds like miraged towers rise.

Zhao: The clouds build a high tower at sea.

Liu: And the shapeless clouds of the sky form mirages yonder.

Obata: And the rising clouds that build palaces and towers,

Alley: stare at the picture a cloud forms of a sea with a tall tower standing up from it;

Bynner \& Kiang: Sea-clouds gleam like palaces,

Observing all the translations, we can find that only $\mathrm{Xu}$ and Bynner \& Kiang change the metaphor in the original into a simile which is concise and clear. To keep the beauty of the original form and meaning, Liu translates the metaphor in the original with metaphorical expressions which is a little longer. As for Alley, he tends to explain one image “海楼” in detail and the translation is created in the form of prose. The translations of Zhao and Obata are similar because metaphorical expressions in their translations are very close to the original one. According to the feature of metaphor in the original, we know the word "结 (build)" should be understood metaphorically. If we translate the word literally, the clouds are metaphorically regarded as people, which can be found in "I Wandered Lonely as a Cloud" by William Wordsworth. That's why Zhao and Obata adopt the literal translation. Based on the above analysis, we can find that when translators translate metaphors that exist in the form of both source domain and target domain, they tend to translate them into metaphors or similes in different ways. 


\section{Conclusion}

Even though a masterpiece of Li Bai's poems, "Travelling Far Away from Mt. Jingmen" has always been ignored. Because the poem is characterized by metaphors, this paper analyzes the metaphors in the poem and then conducts a comparative study of different translations including the metrical ones and the free-verse ones under the guidance of Conceptual Metaphor Theory and Image Schema Theory. As mentioned earlier, metaphors in the poem can be classified into two types. After analyzing these metaphors and their translations, we have discovered the following characteristics:

1) In the translation of the first type, the source domain is kept and translated by more translators, and by doing this, there is no obvious mistake.

2) In the translation of the second type, translators tend to translate them into metaphors or similes in different ways.

From the above characteristics, we can see metaphor translation is feasible in poetry translation. At this point, there are good examples from both the metrical and free verse translations. Also, although the metrical translation tends to be concise in terms of expressions, it's not necessarily inaccurate. And the free-verse translation is not necessarily accurate. Of course, metaphor translation is not easy, so word by word translation is not usually acceptable and translators should adopt proper ways to reproduce the metaphors after comprehending them. As Li Bai's poetry is full of metaphors, the findings in the English translation of the poem can reflect some of their features and may serve as reference for more studies.

\section{About the Authors}

Huang Shanshan is a postgraduate of QX181 in the School of Foreign Studies, Yangtze University.

Wang Feng (corresponding author) is an Associate Professor in the School of Foreign Studies, Yangtze University. His research interests include translation studies, intercultural communication, and interpreting studies.

\section{Conflict of Interest}

The authors declare that there is no conflict of interest.

\section{Funding}

This work was supported by the National Social Science Fund of China under Grant [Key Project 17AZD040].

\section{References}

Alley, Rewi (1980). Li Pai: 200 Selected Poems. Hongkong: Joint Publishing Co., 6.

Bynner, Witter \& Kiang Kang-hu (trans.) (1929). The Jade Mountain: A Chinese Anthology, Being Three Hundred Poems of the T'ang Dynasty, 618 -906. New York: Knopf, 56. 
He, Jie \& Luo Tianni (2016). A Study of Personification Metaphor Translation in Poetry from the Perspective of Conceptual Metaphor Theory. Journal of Southeast University (Philosophy and Social Science), 18(S1): 137-138, 145.

Johnson, M. (1987). The Body in the Mind: The Bodily Basis of Meaning, Imagination, and Reason. Chicago: University of Chicago Press.

Lakoff, G. \& Johnson, M. (1980). Metaphors We Live by. Chicago: University of Chicago Press. Liu, Junping (trans.) (2002). New Versions of Old Gems. Beijing: Zhonghua Publishing House, 68. Liu, Yu \& Yang Wendi (2011). Interpretation of Poetry from the Perspective of Conceptual Metaphor Theory: a Case Study of Li Shangyin's “Jin Se (锦瑟)". Academic Forum, 34(07): 95-98, 103.

Obata, Shigeyoshi (1922). The Works of Li Po, New York: Dutton, 1, 80.

Quan, Xunlian \& Tian Debei (2012). A Study of Translation of Images in Classical Chinese Poetry from the Perspective of Conceptual Metaphor. Journal of Anhui Normal University (Hum.\& Soc. Sci.), 40(01): 127-132.

Shu, Dingfang (2000). Studies in Metaphor. Shanghai: Shanghai Foreign Language Education Press.

Tang, Jun \& He Tingting (2019). A Comparative Study on the Image Translation in “Chun Jiang Hua Yue Ye (春江花月夜)" from the Perspective of Conceptual Metaphor Theory. Journal of Huaibei Normal University (Philosophy and Social Sciences), 40(01): 71-75.

Wang, Feng (2015). A Comprehensive Study on the English Translation of Classical Tang Poetry. Beijing: China Social Sciences Press, 86.

Wang, Yin (2007). Cognitive Linguistics. Shanghai: Shanghai Foreign Language Education Press, 177.

Xu, Yuanchong (trans.) (2007). Selected Poems of Li Bai. Changsha: Hunan People's Publishing House, 13.

Yan, Minfen (2002). Metaphorical Universal in Poetry and Poetry Translation. Foreign Languages and Their Teaching, (10): 43-46.

Zhang, Ninghui (trans.) (1983). Li Bai's Poetry and Its Inner Imagery. Xi'an: Shaanxi People's Publishing House, 1.

Zhao, Yanchun (trans.) A Complete English Translation of Li Bai's Poetry. unpublished. 

or adapt the article content, providing a proper, prominent and unambiguous attribution to the authors in a manner that makes clear that the materials are being reused under permission of a Creative Commons License. Views, opinions and conclusions expressed in this research article are views, opinions and conclusions of the author(s). and European Journal of Literature, Language and Linguistics Studies shall not be responsible or answerable for any loss, damage or liability caused in relation to/arising out of conflicts of interest, copyright violations and inappropriate or inaccurate use of any kind content related or integrated into the research work. All the published works are meeting the Open Access Publishing requirements and can be freely accessed, shared, modified, distributed and used in educational, commercial and non-commercial purposes under a Creative Commons Attribution 4.0 International License (CC BY 4.0). 